\title{
Mathematical modeling of thermal and circulatory effects during hemodialysis.
}

Citation for published version (APA):

Droog, R. P., Kingma, B. R., van Marken Lichtenbelt, W. D., Kooman, J. P., van der Sande, F. M., Levin, N. W., van Steenhoven, A. A., \& Frijns, A. J. (2012). Mathematical modeling of thermal and circulatory effects during hemodialysis. Artificial Organs, 36(9), 797-811. https://doi.org/10.1111/j.15251594.2012.01464.x

Document status and date:

Published: 01/09/2012

DOI:

10.1111/j.1525-1594.2012.01464.x

Document Version:

Publisher's PDF, also known as Version of record

Document license:

Taverne

Please check the document version of this publication:

- A submitted manuscript is the version of the article upon submission and before peer-review. There can be important differences between the submitted version and the official published version of record.

People interested in the research are advised to contact the author for the final version of the publication, or visit the DOI to the publisher's website.

- The final author version and the galley proof are versions of the publication after peer review.

- The final published version features the final layout of the paper including the volume, issue and page numbers.

Link to publication

\footnotetext{
General rights rights.

- You may freely distribute the URL identifying the publication in the public portal. please follow below link for the End User Agreement:

www.umlib.nl/taverne-license

Take down policy

If you believe that this document breaches copyright please contact us at:

repository@maastrichtuniversity.nl

providing details and we will investigate your claim.
}

Copyright and moral rights for the publications made accessible in the public portal are retained by the authors and/or other copyright owners and it is a condition of accessing publications that users recognise and abide by the legal requirements associated with these

- Users may download and print one copy of any publication from the public portal for the purpose of private study or research.

- You may not further distribute the material or use it for any profit-making activity or commercial gain

If the publication is distributed under the terms of Article $25 \mathrm{fa}$ of the Dutch Copyright Act, indicated by the "Taverne" license above, 


\title{
Mathematical Modeling of Thermal and Circulatory Effects During Hemodialysis
}

\author{
$*$ Rens P.J. Droog, $†$ Boris R.M. Kingma, $†$ Wouter D. van Marken Lichtenbelt, \\ $\ddagger$ Jeroen P. Kooman, $¥$ Frank M. van der Sande, §Nathan W. Levin, \\ *Anton A. van Steenhoven, and *Arjan J.H. Frijns
}

\begin{abstract}
*Department of Mechanical Engineering, Eindhoven University of Technology, Eindhoven; $\dagger$ Department of Human Biology, NUTRIM School for Nutrition, Toxicology and Metabolism of Maastricht University Medical Center+, Maastricht University; $\neq$ Department of Internal Medicine and Nephrology, University Hospital Maastricht, Maastricht, The Netherlands; and §Division of Nephrology and Hypertension, Beth Israel Medical Center, Renal Research Institute, New York, NY, USA
\end{abstract}

\begin{abstract}
Intradialytic hypotension (IDH) is one of the most common complications of hemodialysis (HD) treatment. The initiating factor of IDH is a decrease in blood volume, which is related to an imbalance between ultrafiltration (UF) and refilling rate. Impaired reactivity of resistance and capacitance vessels in reaction to hypovolemia plays possibly a major role in the occurrence of IDH. These vessels also fulfill an important function in body temperature regulation. UF-induced cutaneous vasoconstriction would result in a reduced surface heat loss and an increase in core temperature. To release body heat, skin blood flow is increased at a later stage of the HD treatment, whereby possibly IDH can occur. The aim of the study is to develop a mathematical model that can provide insight into the impact of thermoregulatory processes on the cardiovascular (CV) system during HD treatment. The mathematical
\end{abstract}

procedure has been created by coupling a thermophysiological model with a CV model to study regulation mechanisms in the human body during HD + UF. Model simulations for isothermal versus thermoneutral HD + UF were compared with measurement data of patients on chronic intermittent HD $(n=13)$. Core temperature during simulated HD + UF sessions increased within the range of measurement data $\left(0.23^{\circ} \mathrm{C}\right.$ vs. $\left.0.32 \pm 0.41^{\circ} \mathrm{C}\right)$. The model showed a decline in mean arterial pressure of $-7 \%$ for thermoneutral $\mathrm{HD}+\mathrm{UF}$ versus $-4 \%$ for isothermal $\mathrm{HD}+\mathrm{UF}$ after $200 \mathrm{~min}$ during which relative blood volume changed by $-13 \%$. In conclusion, simulation results of the combined model show possibilities for predicting circulatory and thermal responses during HD + UF. Key Words: Cardiovascular modeling-Hemodialysis-Hypotension-Thermoregulation.
Hemodialysis (HD) is the most common method used to treat kidney failure. Severe loss of kidney function is a threat to life and requires removal of toxic waste products and restoration of body fluids toward desired levels. This can be accomplished by dialysis with an artificial kidney. Excess body water, accumulated during the interdialytic period, is removed by blood ultrafiltration (UF). Plasma water depletion induces a decline in relative blood volume (RBV) up to $20 \%$ in a $3-5 \mathrm{~h}$ period, thereby disturbing

doi:10.1111/j.1525-1594.2012.01464.x

Received October 2011; revised January 2012.

Address correspondence and reprint requests to Dr. Arjan J.H. Frijns, Department of Mechanical Engineering, Eindhoven University of Technology, PO Box 513, Eindhoven 5600MB, The Netherlands. E-mail: a.j.h.frijns@tue.nl the cardiovascular (CV) system. Autonomic compensatory responses to hypovolemia involve a decrease in venous vessel capacity to maintain cardiac filling, an increase in vascular resistance to ensure perfusion of critical organs, and an increase in cardiac contractility and rate to optimize heart activity (1). Hypovolemia has been suggested to be the main initiating factor behind intradialytic hypotension (IDH). IDH remains a significant cause of morbidity and patient discomfort in the HD population (2). The underlying mechanisms are not yet fully understood. Nevertheless, several theories have been introduced to explain IDH (3). These include: acute alterations in the autonomic nervous system activity, a decrease in plasma osmolality related to dialysate sodium concentration, a marked fall in cardiac output (CO), impaired venous compliance, and an impaired reactivity of 
capacitance and resistance vessels. The exact role of the capacitance and resistance vessels in the blood pressure response to $\mathrm{HD}$ remains uncertain. In general, an important function of these vessels is related to body temperature regulation. Heat loss across the skin surface is regulated by controlling blood flow in cutaneous blood vessels. In a warm environment, the vessel's diameter is widened. This provides an increase in blood flow to the periphery. As a result, skin temperature rises, which leads to an increase in heat transfer to the environment. Vasoconstriction acts like a defense mechanism in a cold ambient environment. Gotch et al. (4) introduced the hypothesis that during HD, when resistance vessels are constricted due to loss in circulatory blood volume (BV), the regular heat balance is interrupted by means of reduced heat dissipation from the skin, while at the same time the metabolic heat production remains the same. As a consequence, heat is accumulated and core temperature would increase during the dialysis treatment. At a certain threshold, skin vessels would open in order to remove excess heat from the body core. This mechanism counteracts the physiological response to hypovolemia, thereby possibly causing sudden hypotensive episodes during the HD session. Van der Sande et al. showed that the internal heat accumulation might very well be responsible for the impaired vascular response during HD and found that patient stability increases by cooling of the extracorporeal blood flow (5). These observations have led to growing interest in thermal and circulatory effects during HD and the development of several monitoring and controlling strategies. Recent studies showed that BV monitoring devices have a moderate effect on the reduction of the incidence of IDH $(6,7)$. Contraction of splanchnic and possibly splenic vascular beds during HD can compensate part of the reduction of the RBV (7). The role of cool temperature dialysis shows greater promise for reducing the incidence of IDH (6). However, there is still a lot unknown in finding the optimum dialysate temperature.

The hypothesis by Gotch et al. has not yet been verified; in consequence, we developed a mathematical model that accounts for thermal and hypovolemic effects on the CV system during HD + UF. The aim of the study is to develop a mathematical model that can provide insight into the impact of thermoregulatory processes on the $\mathrm{CV}$ system during $\mathrm{HD}$ treatment. Fundamentally, the procedure is based on a coupled thermo-CV model. This approach enables to examine the role of cutaneous vasomotion in the occurrence of IDH. Mathematical models with respect to arterial pressure response to $\mathrm{BV}$ withdrawal have been proposed by Cavalcanti et al. (1) and Ursino and Innocenti (8), but to our knowledge, no models exist where in addition also thermal effects were taken into account.

\section{PHYSIOLOGICAL MODELS}

To characterize physiological behavior of the human body related to thermal and CV response during HD, two models are considered: a thermophysiological (TP) model and a CV model. Both models interact as illustrated in Fig. 1. Changes in heart rate (HR) and BV are used as model inputs. A reduction in HR leads to a decrease in CO. Plasma water removal reduces circulatory $\mathrm{BV}$, after which right atrial pressure $\left(p_{r a}\right)$ tends to decline. Low right atrial pressure decreases stroke volume and therefore CO (Frank-Starling effect) (9); as a consequence, arterial pressure $\left(p_{a}\right)$ drops. To compensate for low blood pressure, baroreceptors generate impulses to increase total peripheral resistance (TPR) by vasoconstriction and to decrease unstressed venous volume $\left(V_{v u}\right)$. These baroreceptor pathways are indicated by dotted lines in the scheme. Hypothalamus temperature $\left(T_{h y}\right)$ is considered as core temperature, which will decrease if TPR declines and vice versa.

\section{TP MODEL}

During current research, ThermoSEM (10) is used to simulate thermoregulation in a human body. The model's fundamentals are based on the Fiala model $(11,12)$. From the mathematical point of view, the human thermoregulation model can be separated into a passive system and a controlling active system, in a similar way as is done in the Fiala model.

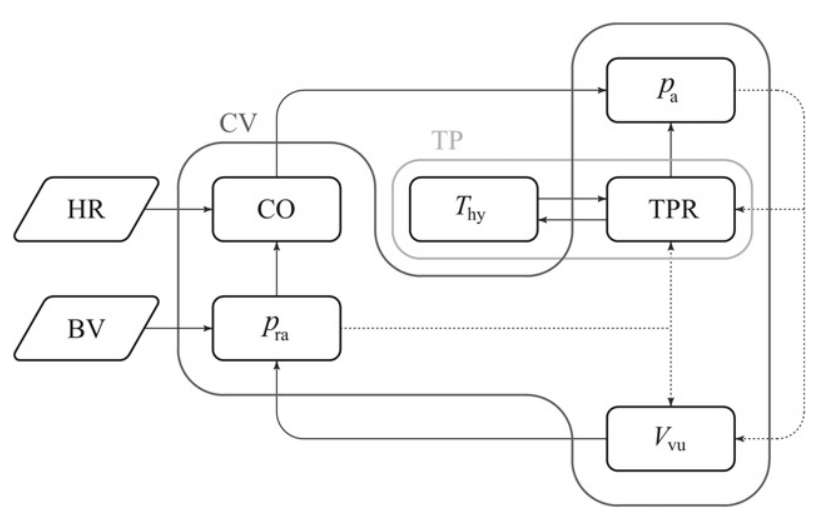

FIG. 1. Dependency scheme for CV variables and thermoregulation. Frames indicating the two different models; the dark gray frame indicates the CV model and the gray frame represents the TP model. Mechanisms under baroreflex control are indicated by dotted lines. 


\section{Passive system}

The passive system accounts for environmental heat exchange via conduction, convection, radiation, and evaporation, and for the conduction and convection via the blood within the body elements. A characteristic geometry of the humanoid was achieved by lumping the body into 19 segments: a sphere for the head and 18 cylinders symbolizing the trunk and limbs (Fig. 2). All segments consist of multiple concentric layers, representing different tissue types, from the inside out: bone, muscle, fat, inner skin, and outer skin. The thermal properties of these tissues are known and can be found in literature. We used the values described in Fiala et al.'s study (11). The segments are divided into three sectors whereupon asymmetric boundary conditions can be applied.

Pennes (13) introduced a modification to the heat equation that accounts for metabolic heat generation and the exchange of heat between flowing blood and surrounding tissue:

$$
\rho c \frac{\partial T}{\partial t}=k \nabla^{2} T+\rho_{b} c_{b} w_{b}\left(T_{a}-T\right)+q
$$

where $\rho, c$, and $k$ are density, specific heat, and thermal conductivity, respectively. $T$ is the local tissue temperature and $T_{\mathrm{a}}$ is the temperature of the perfusing blood. $w$ is the volumetric perfusion rate, $q$ is the metabolic heat production, and subscript "b" describes a blood property. The first term of the righthand side of Eq. 1 describes the heat conduction within the tissues, the second term describes the convective heat transfer between the blood and the tissues, and the third term describes the heat generation within the tissues.

Solving Pennes' heat equation for the body elements requires information of thermal energy transfer (ET) between skin surface and environment by convection, radiation, and evaporation. The model

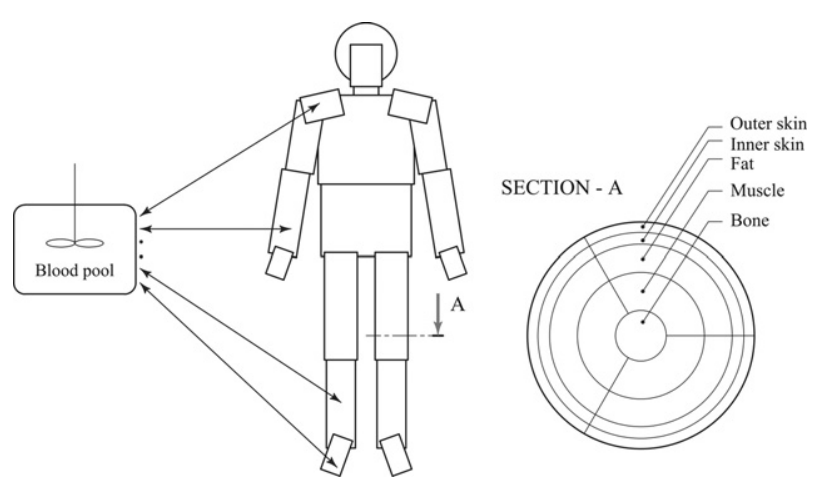

FIG. 2. Construction of the passive human body model. also includes convective heat transfer by the blood in the capillary beds (10). Systemic blood circulation has a tremendous influence on heat dissipation within the body. It prevents overheating in tissues with high metabolic rate (e.g., the brain). In the present model, blood flow was modeled by a central blood pool from which the body elements receive warm blood (12). During a time period, blood exchanges heat with the cutaneous tissue before it flows back to the central blood pool (Fig. 2). By way of counter current heat exchange, the arterial blood is cooled by the adjoining veins; this allows a more realistic distribution of arterial blood temperature compared with assuming a constant arterial blood temperature for the whole body $(10,11,14)$.

In the TP model, convective heat exchange $\left(q_{\text {convection }}\right)$ between the body surface of temperature $T_{s f}$ and the moving air of temperature $T_{a i r}$ is modeled by:

$$
q_{\text {convection }}=A h_{c, \text { mix }}\left(T_{s f}-T_{\text {air }}\right)
$$

where $A$ is the surface area and $h_{c, \text { mix }}$ is the mixed convection coefficient obtained from Fiala et al. (11). The radiative heat flux between the body surfaces and its environment is described by:

$$
q_{\text {radiation }}=A h_{r}\left(T_{s f}-T_{e n v}\right)
$$

where $T_{e n v}$ is the mean temperature of the surroundings and $h_{r}$ is the radiative heat transfer coefficient (11). This radiative heat transfer coefficient is also dependent on the temperatures. Despite the relatively low temperatures in the human body, radiation is responsible for almost $60 \%$ of total heat loss, for a sitting nude person at normal room temperature (4).

In the superficial cutaneous layer where sweat glands are located, moisture evaporation always takes place. The latent energy transport from a skin sector depends on the heat of evaporation of water, the water vapor pressure at the skin surface, and the ambient air, $p_{s k i n, s f}$ and $p_{\text {air }}$, respectively:

$$
q_{\text {evaporation }}=A U_{E}\left(p_{\text {skin, }, f}-p_{\text {air }}\right)
$$

where $U_{E}$ is the resultant evaporation coefficient of clothing covering the sector and the mass transfer resistance through the air near the skin (11).

Finally, the model for respiration heat losses takes two heat loss mechanisms into account, that is, latent heat of vaporization of water $\left(E_{\text {respiration }}\right)$ and pulmonary ventilation $\left(C_{\text {respiration }}\right)$ as a function of metabolic rate $M_{r}(11)$ :

$$
q_{\text {respiration }}=E_{\text {respiration }}+C_{\text {respiration }}
$$


where the evaporative respirative heat loss is given by

$$
\begin{aligned}
E_{\text {respiration }}= & 3.44 \int M_{r} d V\left(2.7710^{-2}+\right. \\
& \left.6.510^{-5} T_{\text {air }}-4.9110^{-6} p_{\text {air }}\right)
\end{aligned}
$$

The convective respirative heat loss is given by

$$
\begin{aligned}
C_{\text {respiration }}= & 1.43910^{-3} \int M_{r} d V(32.6- \\
& \left.0.934 T_{\text {air }}-1.9610^{-4} p_{\text {air }}\right)
\end{aligned}
$$

\section{Active system}

The human body is capable of keeping the core temperature within close limits $\left(36.8 \pm 0.6^{\circ} \mathrm{C}\right)(15)$. Body temperature is controlled by nervous feedback systems and operates through temperature regulation centers located in the hypothalamus. Output signals are used to balance heat production against heat loss. Heat production is in principle a by-product of metabolism. Temperature and heat production due to cell metabolism are coupled with the van't Hoff $Q_{10}$ relation, which states that for every $10^{\circ} \mathrm{C}$ decrease in tissue temperature, cell metabolism is reduced by a factor $Q_{10}(11,16)$. When the rate of heat production in the body is higher than the rate at which heat is being lost, heat builds up in the body and as a consequence core temperature rises. Conversely, when heat loss is higher, body temperature decreases. In cold conditions, the human body reacts by means of shivering and vasoconstriction. In a warm environment, the temperature control system uses vasodilatation of skin blood vessels and sweating to release body heat when body temperature becomes too high. All these mechanisms are incorporated in the active system of the TP model. The present active model operates with so-called error signals introduced by Stolwijk (17). An error signal equals the difference between the actual state of a variable $x$ and its setpoint $x_{\mathrm{o}}$, where the model tries to minimize the error functions.

\section{Perfusion}

In the bioheat equation (Eq. 1), $w_{b}$ appears as the blood perfusion rate. During thermoneutral conditions, tissues are supplied at a perfusion rate $w_{b, 0}$; in the case of non-neutral thermal conditions the flow $w_{b}$ varies with changes in local metabolic rates. Experiments from Rowell and Wyss (18) showed that perfusion is linearly related to metabolism, therefore the current model directly considers the energy equivalent change in the factor $\Delta \beta_{i}=\rho_{\mathrm{b}} c_{\mathrm{b}} \Delta w_{\mathrm{b}, i}$ as a function of the change in metabolism $\Delta q_{i}$ :

$$
\Delta \beta_{i}=\mu_{b} \Delta q_{i}
$$

Factor $\mu_{b}$ was obtained from Stolwijk (17).

\section{Vasomotion}

The rate of blood flow into the skin venous plexus can vary remarkably from almost zero to as great as $30 \%$ of the CO (19). By expressing the local skin blood flow $\left(S B F_{i}\right)$ in terms of the energy-equivalent $\beta_{i}$, one obtains (12):

$$
\beta_{i}=\rho_{b} c_{b} S B F_{i}=\frac{\beta_{i, 0}+a_{d l, i} D l}{1+a_{c s, i} C s \exp (-\eta D l)} Q_{10}^{\frac{T_{s k i}-T_{s k, i, 0}}{10}}
$$

where $\beta_{i, 0}$ arises from the basal skin blood flow; $a_{\mathrm{cs}, i}$ and $a_{d l, i}$ are distribution coefficients; $T_{s k, i}$ and $T_{s k, i, 0}$ are the actual and the reference skin temperature of the $i$-th skin sector, and $D l$ and $C s$ represent the overall responses of peripheral vasodilatation and vasoconstriction, respectively. Vasoconstriction increases cutaneous resistance and therefore reduces SBF. As a consequence, heat is retained in the body core. The expression for $C s$ was taken from Fiala (20).

$$
\begin{aligned}
C s= & 35\left[\tanh \left(0.34 \Delta T_{s k, m}+1.07\right)-1\right] \Delta T_{s k, m}+ \\
& 3.9 \Delta T_{s k, m} \frac{d T_{s k, m}}{d t}
\end{aligned}
$$

In medium hot environments, dilatation leads to an increase in SBF that causes heat to be transferred from the core to the skin, again also the expression for $D l$ was taken from Fiala (12):

$$
\begin{aligned}
D l= & 21\left[\tanh \left(0.79 \Delta T_{s k, m}-0.70\right)+1\right] \Delta T_{s k, m}+ \\
& 32\left[\tanh \left(3.29 \Delta T_{h y}-1.46\right)+1\right] \Delta T_{h y}
\end{aligned}
$$

\section{Sensitivity analysis}

For the TP model, a sensitivity analysis was done for the effects of individual body composition (mass, height, body fat percentage, and resting metabolic rate). A full description can be found in van Marken Lichtenbelt et al.'s study (21). The main conclusions were that the maximum impacts of body mass, body fat percentage, and resting metabolic rate on the mean skin temperature are of comparable order of magnitude (maximum $1.2-1.5^{\circ} \mathrm{C}$ ), whereas the impact of body height is less pronounced (maximum $0.4^{\circ} \mathrm{C}$ ). Core temperatures are just slightly affected. The influence of tissue properties was not investigated, because they hardly change between individuals and can be adequately measured. 


\section{HD equipment heat exchange}

An extension of the TP model has been made for the incorporation of HD equipment. Current research is focused on thermal and CV response during HD treatment, therefore only BV reduction by way of UF and thermal effects of the HD equipment are modeled. In clinical practice, a blood temperature monitor controls the temperature of the patient by adjusting the dialysate temperature. Several methods have been introduced to control patient core temperature, these include: thermoneutral (no ET from patient to extracorporeal circuit), constant core temperature, and constant dialysate temperature $(22,23,32)$. The HD heat exchange model controls the body's core temperature by controlling the blood temperature in the venous line. ET can be calculated by use of Eq. 12 (23):

$$
E T=\rho_{b} c_{b} Q_{d i a, b}\left(T_{d i a, b, \text { out }}-T_{\text {dia, }, \text {,in }}\right)
$$

where $Q_{d i a, b}$ is the blood flow through the dialysis machine, $T_{d i a, b, i n}$ is the ingoing blood temperature in the arterial line, and $T_{\text {dia,bout }}$ is the outgoing temperature of the blood in the venous line. Because the ultrafiltration rate (UFR) is small compared with $Q_{d i a, b}$, we neglect the heat that is removed by UF (24). In the original model, arterial blood exchanges heat with the surrounding tissues by convection in the capillary beds only. The venous blood collects in the major veins and is rewarmed by heat from the adjacent arteries as it flows back to the central blood pool. It mixes with blood from all elements to produce the new central blood pool temperature. In the modified TP model with HD heat exchange, a part of the CO equal to $Q_{d i a, b}$ with temperature $T_{d i}$. $a, b$, out is assumed to mix with blood coming from all other body parts before it flows back to the central blood pool. $T_{\text {dia,b,out }}$ is lowered by the control model when $T_{h y}$ exceeds its baseline value. This concept allows the incorporation of the heat exchange by the HD equipment.

\section{CV model}

In order to analyze the $\mathrm{CV}$ response to hypovolemia, Cavalcanti and Di Marco (25) developed a mathematical model to simulate arterial blood pressure changes induced by HD + UF. Changes in HR and $\mathrm{BV}$ reduction obtained by measurements were used as model inputs. They proposed a physiologically based procedure that is able to reproduce patient-specific measurement data during HD sessions (CO, TPR, and change in unstressed venous volume) by fitting three patient-dependent sensitivity variables $\left(K_{a f f}, K_{r}\right.$, and $\left.K_{v}\right)$ with an iteration algorithm. In this model, the CV system is described by Guyton et al.'s classical models (9) based on the Windkessel theory by Otto Frank (26). The systemic circulation is lumped in a few compartments to itemize only the most relevant circulatory districts. To mimic the main short time pressure regulatory mechanisms, the model includes Starling's law, inotropic heart regulation, and baroreflex control of resistance and capacitance vessels. When the CV system is stressed by the loss of circulatory BV, as occurs during HD + UF, venous capacity can actively be constricted. This mechanism compensates for changes in circulatory $\mathrm{BV}$ due to an increase in vasomotor tone (27). In particular, splanchnic and cutaneous vessels have a variable blood storage function. Increased TPR during hypovolemia raises pressure in the arterial circulation. When BV declines, a rise in HR can also compensate for a drop in arterial pressure.

As the heart fills with less blood than usual, the force of cardiac muscular contractions decreases. This is a result of a decrease in the load experienced by the heart muscle fiber due to the lower amount of blood entering the heart. Changes in inotropic heart activity produce considerable changes in stroke volume, which is known as the Frank-Starling effect. This effect is predominantly responsible for the decrease in $\mathrm{CO}$ during $\mathrm{HD}+\mathrm{UF}$.

The current CV model is based on this model proposed by Cavalcanti and Di Marco (25) where it has been extended with additional temperaturedependent resistances for the cutaneous and arteriole circulation. By means of this concept, thermal effects on the CV system are incorporated. A patientspecific compartment has been added for the arteriovenous fistula (Fig. 3). The original iterative character is adapted by assuming the three patient-dependent variables in advance to achieve a predictive model behavior.

\section{Cardiac pump}

Because the hemodynamic response under study involves much slower dynamics than the HR period, the pulsating nature of the cardiac pump can be averaged out and the heart can be modeled as a continuous pump. Then, the CV model's $\mathrm{CO} Q_{c o, c v}$ is expressed by relationship 13 (27):

$$
Q_{c o, c v}=Q_{s a t}\left[1-\exp \left(-\frac{p_{r a}-p_{r a s}}{p_{r a n}}\right)\right]
$$




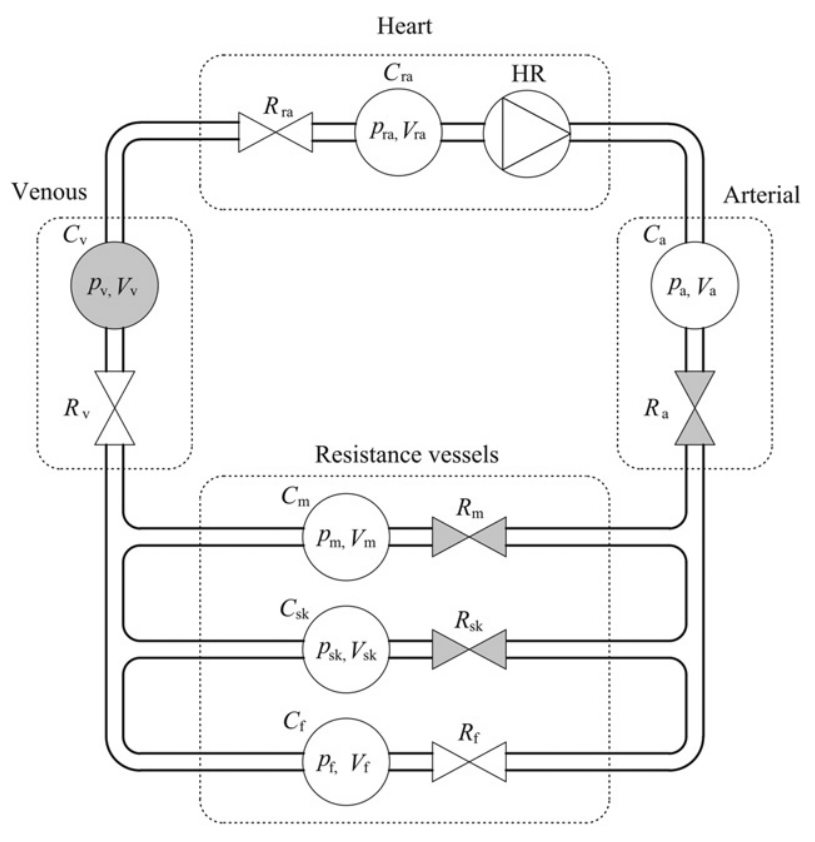

FIG. 3. Hydraulic equivalent of the CV model. The heart with HR is represented by a single compartment (right atrium) continuous pump. The compliances are depicted by $C_{i}$ (with $\mathrm{i}=$ arterial [a], microcirculatory [m], skin [sk], fistula [f], venous [v], or right atrium [ra]), the resistances by $R_{i}$, and the pressures in each compartment by $p_{i}$. Only the shaded elements are affected by regulation mechanisms.

in which $Q_{s a t}$ is the saturation level, $p_{r a}$ is the right atrial pressure, $p_{\text {ras }}$ is the pressure for null $\mathrm{CO}$ (no flow through the heart), and $p_{\text {ran }}$ is a sensitivity parameter that determines the sensitivity of $\mathrm{CO}$ to right atrial pressure (27). The inotropic effect of the heart is taken into account by a sigmoid function of the HR, which modulates the saturation level $\left(Q_{\text {sat }}\right)$ of the cardiac curve (27):

$$
Q_{s a t}=Q_{m}\left[1+3 K_{c o} \tanh \left(2 \frac{f-f_{e}}{f}\right)\right]
$$

in which $Q_{m}$ is the maximum $\mathrm{CO}$ at the beginning of the simulation, $f$ is the current $\mathrm{HR}$, and $f_{\mathrm{e}}$ is the $\mathrm{HR}$ at the beginning of the dialysis. $K_{c o}$ represents the sensitivity parameter of HR to $Q_{\text {sat }}$. By using these two expressions, a proper fit on dynamic physiological heart curve data is accomplished.

\section{Systemic circulation}

The model as shown in Fig. 3 shows an anatomical analogy with the blood flow from the heart to the aorta, which branches in several medium-sized arteries and in thermo-sensitive arterioles with variable resistance $R_{a}$. Compartments in parallel arrangement represent the resistance vessels. They account for the systemic capillaries in the cutaneous and splanchnic region, whereas the fistula can be considered as a bypass of the latter. Venous circulation starts with the venules and medium-sized veins from where the blood ultimately discharges into the inferior vena cava.

The mathematical circulatory system model consists of six compartments, respectively: right atrium (ra), arterial (a), microcirculatory (m), skin (sk), fistula (f), and venous (v). Each compartment is modeled as an elastic chamber with a specific volume and compliance $C_{i}$ to account for the capacitive properties of the circulation. Blood can flow in or out of these compartments through hydraulic resistances. Shaded elements in the figure indicate time varying quantities under regulation. In general, each compartment of the CV system can be described by its resistance to flow $R_{i}$, defined by the relation:

$$
Q_{i}=\frac{\Delta p_{i}}{R_{i}}
$$

where $\Delta p_{i}$ is the pressure drop between the two compartments and $Q_{i}$ is the flow through the resistance $R_{i}$, which links them. The system of ordinary differential equations describing the $\mathrm{CV}$ model dynamics is obtained by applying the law of mass conservation:

$$
\begin{gathered}
\frac{d V_{a}}{d t}=Q_{c o, c v}-\frac{p_{a}-p_{m}}{R_{e q}} \\
\frac{d\left(V_{m}+V_{s k}+V_{f}\right)}{d t}=\frac{p_{a}-p_{m}}{R_{e q}}-\frac{p_{m}-p_{v}}{R_{v}} \\
\frac{d V_{r a}}{d t}=\frac{p_{v}-p_{r a}}{R_{r a}}-Q_{c o, c v}
\end{gathered}
$$

In this set of equations, $Q_{\mathrm{cocc}}$ is the $\mathrm{CV}$ model's $\mathrm{CO}$ described by Eq. 13. $V_{i}$ represents the compartment volume, $R_{i}$ is the resistance, and $p_{i}$ is the pressure. Due to the parallel arrangement of the microcirculatory, fistula, and skin compartments, the pressures in there are equal. Before solving the system, $R_{e q}$ is calculated as the equivalent resistance between the arterial and parallel chambers:

$$
R_{e q}=R_{a}+\left(\frac{1}{R_{m}}+\frac{1}{R_{s k}}+\frac{1}{R_{f}}\right)^{-1}
$$

Model equations were solved numerically using the one-step Adams-Bashforth method with constant time step. For each compartment, pressure is calculated by: 


$$
p_{i}=\frac{V_{i}-V_{i u}}{C_{i}} \text { with } i=\mathrm{a}, \text { eq, } \mathrm{v}, \text { ra for } V_{i} \geq V_{i u}
$$

in which $V_{\text {iu }}$ is the unstressed volume of compartment $i$. Arterial pressure $\left(p_{\mathrm{a}}\right)$ was in accordance with other studies $(1,25,27)$ considered as mean arterial pressure (MAP).

\section{Baroreflex control}

The compensatory mechanisms are initiated by two types of receptors: one by cardiopulmonary baroreceptors located in the atria and the main pulmonary veins, the other by arterial baroreceptors located in the aortic arch and carotid sinus. In case of low blood pressure, the cardiopulmonary and arterial baroreceptors discharge leads to the generation of efferent signals, affecting the CV system parameters (i.e., HR and contractility, microcirculatory resistance $R_{m}$, skin resistance $R_{s k}$, and unstressed venous volume $V_{v u}$ ) (1). Variations of $p_{a}$ and $p_{r a}$ are compared with the values at the beginning of the treatment to actuate the static vasomotor tone $\theta_{s}$, as shown in Eq. 21:

$$
\theta_{s}=\left(1-K_{a f f}\right) \frac{p_{a}-p_{a e}}{p_{a e}}+\left(1+K_{a f f}\right) \frac{p_{r a}-p_{r a e}}{p_{r a e}}
$$

where $p_{a e}$ and $p_{\text {rae }}$ indicate arterial and atrial pressure at the beginning of the dialysis, when the CV system is in equilibrium. By changing the model parameter $K_{\text {aff }}$ from -1 to 1 , a different relative weight can be assigned to the afferents. When $K_{a f f}$ is equal to -1 , the cardiopulmonary afferent is completely inhibited and the control is executed by the arterial side only. When $K_{\text {aff }}$ is equal to 0 , the afferents are exactly balanced. The typical baroreflex control dynamics are modeled with a first order filter (Eq. 22) where $\tau$ is a time constant (10 s).

$$
\frac{d \theta_{d}}{d t}=\frac{1}{\tau}\left(\theta_{s}-\theta_{d}\right)
$$

Efferent regulations were modeled by sigmoid functions suitable for obtaining linear behavior for small pressure perturbations and the typical saturation effects for large perturbations (27):

$$
\begin{aligned}
& R_{m}=R_{m e}\left[1-K_{r} \tanh \left(2 \theta_{d}\right)\right] \\
& V_{v u}=V_{\text {vue }}\left[1+K_{v} \tanh \left(2 \theta_{d}\right)\right]
\end{aligned}
$$

With $V_{\text {vue }}$ and $R_{m e}$, the unstressed venous volume and the microcirculatory resistance at the beginning of the dialysis when $\theta_{d}$ equals 0 . The balance param-

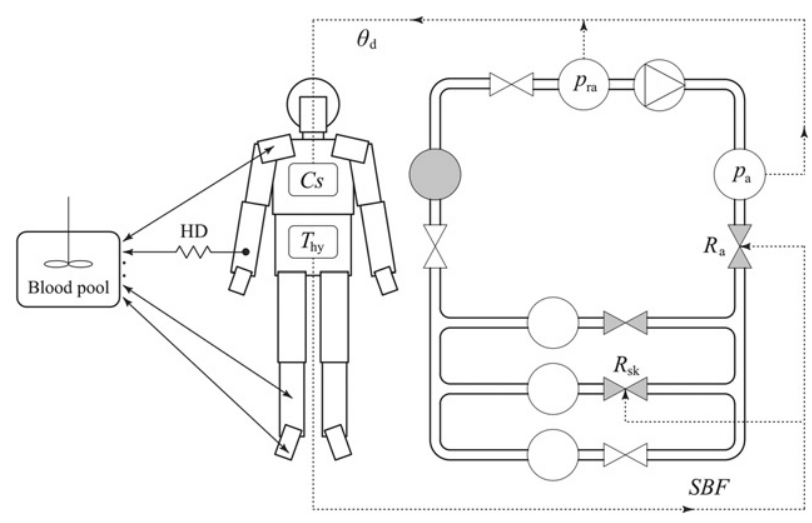

FIG. 4. Schematic interaction between both models. Baroreceptor pressure signals as function of right atrial pressure $\left(p_{\text {ra }}\right)$ and arterial pressure $\left(p_{a}\right)$ are transferred by vasomotor tone $\theta_{\mathrm{d}}$ to the TP model where they alter the vasoconstriction $(C s)$ function. Body temperature-dependent SBF predicted by the TP model is used to adjust skin resistance $\left(R_{s k}\right)$ and arteriole resistance $\left(R_{a}\right)$. Heat withdrawal and blood flow through the HD machine is indicated by the zigzag line.

eter $K_{a f f}$ of the afferent pathways and the gains $K_{r}$ and $K_{v}$ express the efficiency in the overall regulation of vasoconstriction. The values of $K_{a f f}, K_{r}$, and $K_{v}$ were chosen to best fit mean experimental data from van der Sande et al. (5). At last, new values for $V_{\mathrm{vu}}$ and $R_{\mathrm{m}}$ for the next time step are obtained.

\section{COUPLING OF CV AND TP MODEL}

$\mathrm{CV}$ reactivity closely depends on changes in thermal state of the body and vice versa. Hypovolemic-induced cutaneous vasoconstriction in the TP model is achieved by incorporation of baroreceptor signals from the atrial and arterial compartment (Fig. 4). These signals are translated to dynamic vasomotor tone $\theta_{d}$. In the $\mathrm{CV}$ model, thermosensitive resistances have been added. Cutaneous resistance $\left(R_{s k}\right)$ and arteriole resistance $\left(R_{a}\right)$ are forced to vary with total SBF predicted by the TP model. Hence, blood pressure changes can be predicted as a consequence of alterations in hypothalamus temperature $\left(T_{h y}\right)$. Heat withdrawal and blood flow through the dialysis machine is visualized by the zigzag line between the blood pool and the right lower arm (Fig. 4).

\section{Thermal to $\mathbf{C V}$}

Heat transfer to the skin by the blood is controlled by the degree of vasoconstriction of the arterioles and the arteriovenous anastomoses that supply blood to the venous plexus of the skin. Constriction of these vessels effects TPR and thereby 
MAP. Modeling this mechanism is achieved by adding two additional body temperature-dependent resistances $R_{s k}\left(\Delta T_{h y}\right.$ and $\left.\Delta T_{s k}\right)$ and $R_{a}\left(\Delta T_{\text {hy }}\right.$ and $\left.\Delta T_{s k}\right)$ to the original Cavalcanti model (1) (Fig. 3). $R_{s k}$ represents resistance to flow through the systemic cutaneous circulation and $R_{a}$ is the arteriole resistance at the end of the aorta. Because they are closely related in cutaneous blood flow regulation, $R_{a}$ is assumed to vary linearly with $R_{s k}$ as a first assumption: $R_{a}=\varphi R_{s k}$ where $\varphi$ is introduced as proportionality factor. During HD + UF, CO can decrease up to $40 \%$ (5). This phenomenon is incorporated in the cardiac curve of the $\mathrm{CV}$ model, in contrast to the TP model where constant $\mathrm{CO}$ is assumed. For this reason, skin blood flow from the TP model is scaled to the CO predicted by the $\mathrm{CV}$ model on each timestep. Hence, an underlying assumption in here is that $\mathrm{SBF}$ reduction is linear proportional to the decrease in $\mathrm{CO}$ in the course of the HD procedure. This approach enables to translate changes in SBF in the TP model to the CV model where the corresponding resistance is calculated to fit the scaled SBF for each time step:

$$
R_{s k}=\frac{\left(Q_{c o, c v}-Q_{s k, c v}\right)}{Q_{s k, c v}\left[\frac{1}{R_{f}}+\frac{1}{R_{m}}\right]}
$$

in which the scaled skin blood flow is:

$$
Q_{s k, c v}=Q_{s k, t p}\left(\frac{Q_{c o, c v}}{Q_{c o, c v, 0}}\right)
$$

In this equation, $Q_{c o, c v}$ is the current $\mathrm{CO}$ on timestep $t$ and $Q_{c o, c v, 0}$ is the $\mathrm{CO}$ at the beginning of the dialysis when the CV system is in stationary state, the ratio between them can be considered as a scale factor. $Q_{s k, t p}$ is the SBF simulated by the TP model for a certain thermal state of the body.

\section{CV to thermal}

In hypovolemic state, reflexes from baroreceptors stimulate the vasoconstrictor system throughout the body including blood vessels in the cutaneous circulation (28). Figure 5 shows how static vasomotor tone $\theta_{s}$ is transformed to typical dynamic vasomotor tone $\theta_{d}$ by a low pass filter. Sigmoid functions account for change in unstressed venous volume, microcirculatory resistance, and the vasoconstriction as function of $\theta_{d}$. To incorporate hypovolemic-induced cutaneous vasoconstriction, an adaption has been made on the Cs function in the TP model:

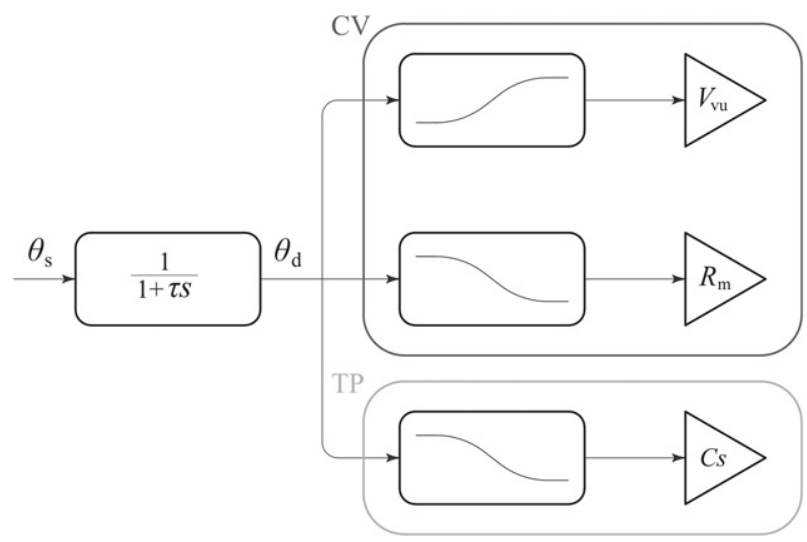

FIG. 5. Static vasomotor tone signal $\left(\theta_{\mathrm{s}}\right)$ is translated via a low pass filter into dynamic vasomotor tone $\left(\theta_{d}\right)$ that incorporates the typical dynamics of vasomotor regulation. Thereafter, unstressed volume, microcirculatory resistance, and the vasoconstriction function (Cs) are adapted. Dark gray frame: CV model; gray frame: TP model.

$$
\begin{aligned}
C s= & \left.35\left[\tanh \left(0.34 \Delta T_{s k, m}+1.07\right)-1\right] \Delta T_{s k, m}\right] \\
& +3.9 \Delta T_{s k, m} \frac{d T_{s k, m}}{d t}+K_{c s} \tanh \left(\alpha_{c s} \theta_{d}\right)
\end{aligned}
$$

The sigmoid function on the right-hand side of Eq. 27 has been added to Eq. 10. This concept allows forcing the forearm SBF to change in accordance with mean experimental data (22) during thermoneutral HD + UF, where the factor $K_{c s}$ determines the saturation level and $\alpha_{c s}$ is the gradient of the curve. Hence, these coefficients determine indirectly the amount of hypovolemic-induced SBF reduction during treatment.

\section{Initial and parameter value assignment}

To accomplish a physiologically realistic numerical simulation, a strategy for assigning values to model parameters was established. All parameter values were verified to correspond with physiological data. For the CV model, constants are based on Cavani et al. (27); for data values regarding the TP model a reference is made to Severens (10). Heart curve, initial mean arterial pressure $\left(\mathrm{MAP}_{0}\right)$, and baroreflex control parameters were assigned a priori. HR data and the decline in BV during treatment were used as model inputs. Decay in total BV was prescribed linearly which, according to experimental evidence, turns out to be a reasonable assumption (29). HR was assumed constant in time because mean experimental data show a comparable trend (22). As a starting point, heart curve parameters in Eq. 13 were identified to obtain the best fit on cardiac curves from physiological data $(5,19)$. Furthermore, the 
TABLE 1. Initial blood volume $\left(\mathrm{V}_{\mathrm{i}}\right)$ percentage distribution, resistance values $\left(\mathrm{R}_{\mathrm{i}}\right)$, and compliance values $\left(\mathrm{C}_{\mathrm{i}}\right)$

\begin{tabular}{lccc}
\hline Compartment $i$ & $V_{i}(\%)$ & $R_{i}(\mathrm{~mm} \mathrm{Hg} \mathrm{s} / \mathrm{mL})$ & $C_{i}(\mathrm{~mL} / \mathrm{mm} \mathrm{Hg})$ \\
\hline Arterial & 18 & 0.16 & 1.0 \\
Microcirculatory & 4 & 0.6 & 9.2 \\
Venous & 59 & 0.22 & 20.6 \\
Atrial & 13 & 0.09 & 33.1 \\
Skin & 6 & 9.0 & 9.2 \\
Fistula & 0 & 3.6 & 0.01 \\
\hline
\end{tabular}

percentage of distribution between the six compartments as well as compliance values $C_{i}$ were determined in accordance with human physiological data similar to those used in previous studies (25) (Table 1). Total circulatory BV was estimated with respect to patient body weight $(52 \mathrm{~mL} /$ $\mathrm{kg})(25)$.

Unstressed volume of the arterial compartment $V_{a u}$ originates from the initial arterial pressure $p_{a e}$ and Eq. 20. Unstressed volume in the microcirculatory compartment $V_{m u}$ was $4.5 \mathrm{~mL} / \mathrm{kg}$ body weight (25). The unstressed volume of the right atrium $V_{\text {rau }}$ was calculated with use of Eq. 20 by substituting the right atrial pressure when the $\mathrm{CV}$ system is in equilibrium at the beginning of the dialysis when venous return equals CO. Volume of the fistula $V_{f}$ was assumed to be very small compared with the total $\mathrm{BV}\left(V_{t o t}\right)$ and was therefore neglected. Compliance of the fistula $C_{f}$ was assumed to be close to zero because the vessel's wall becomes very stiff as the fistula matures. To estimate cutaneous compliance, the same value was taken as for the microcirculation. Finally, values for resistances $R_{i}$ with $i=\mathrm{eq}, \mathrm{v}$, ra were obtained by imposing the equilibrium condition of the model at the beginning of the dialysis. $R_{f}$ was chosen to fit a typical fistula flow $(1.0 \mathrm{~L} / \mathrm{min})$. The initial value for cutaneous resistance $R_{\text {ske }}$ is calculated to fit basal SBF predicted by the TP model for a person in thermal neutral condition when the CV system is in stationary state. Experimental data (30) of thermal-induced blood pressure changes were used to determine proportionality factor $\varphi$ by fitting this coefficient on the amplitude of MAP. The three baroreflex control parameters were selected to best fit the mean dialysis data for stable subjects obtained from van der Sande et al. (22). Distribution coefficients $a_{c s}$ and $a_{d l}$ of all body parts were assumed to be the same as in Fiala et al.'s study (12), implying that hypovolemic cutaneous vasoconstriction over all body parts is assumed to react the same as in case of thermalinduced vasoconstriction.
The combined CV-TP model was implemented in Matlab.

\section{THERMAL-INDUCED BLOOD PRESSURE CHANGES (EVALUATION 1)}

To evaluate the CV model with thermal effects, experimental datasets obtained in a climate tent setup (30) are compared with simulated blood pressure in response to heating and cooling. The subgroup of elderly was chosen because they best reflect the HD population group. The main objective is evaluating the $\mathrm{CV}$ model toward predicting blood pressure changes caused by heating and cooling. The fistula is omitted in the simulations because experimental data are obtained from healthy subjects, hence $\mathrm{R}_{f} \rightarrow \infty$.

As initial conditions, we use the thermo-neutral state, because the test protocol for healthy volunteers is designed such that they were in thermo neutral situation at the start (30). For the simulations, we used the body characteristics of an average man: a height of $1.71 \mathrm{~m}$, body mass of $73.5 \mathrm{~kg}$, body fat percentage of $14.4 \%$, and metabolic rate of $87.1 \mathrm{~W}(21)$.

\section{Materials and methods}

Twelve healthy elderly men volunteers participated in the study as described in Kingma et al.'s study (30). Two were rejected because an incomplete dataset was obtained. Ultimately, 10 subjects (age $=70.9 \pm 4.2$ year) were included. They stayed in a climate tent (CAT-430 Colorado Altitude Training, Louisville, CO, USA) for $3.5 \mathrm{~h}$ in supine position. Air temperature was controlled by means of two air heaters and one air conditioner unit. Blood pressure was measured every $10 \mathrm{~min}$ with a digital sphygmomanometer with automatic inflation (Cresta, Taipei, Taiwan). Subjects were exposed to temperature protocols P1 and P2 (Fig. 6). During tests subjects were dressed in briefs only $(0.04$ clo $)$. The study protocol was approved by Maastricht University Medical Ethical Committee, and an informed consent was given by the subjects. For a more detailed description of these experiments, a reference is made to Kingma et al. (30).

\section{Results}

Protocols P1 and P2 were simulated by the combined TP-CV model based on measured environmental conditions (ambient air temperature, wall temperature, airspeed, and relative humidity). Because the MAP at the beginning of the measurements $\left(\mathrm{MAP}_{0}\right)$ was different for each subject, MAP was normalized for this initial value. Results for 

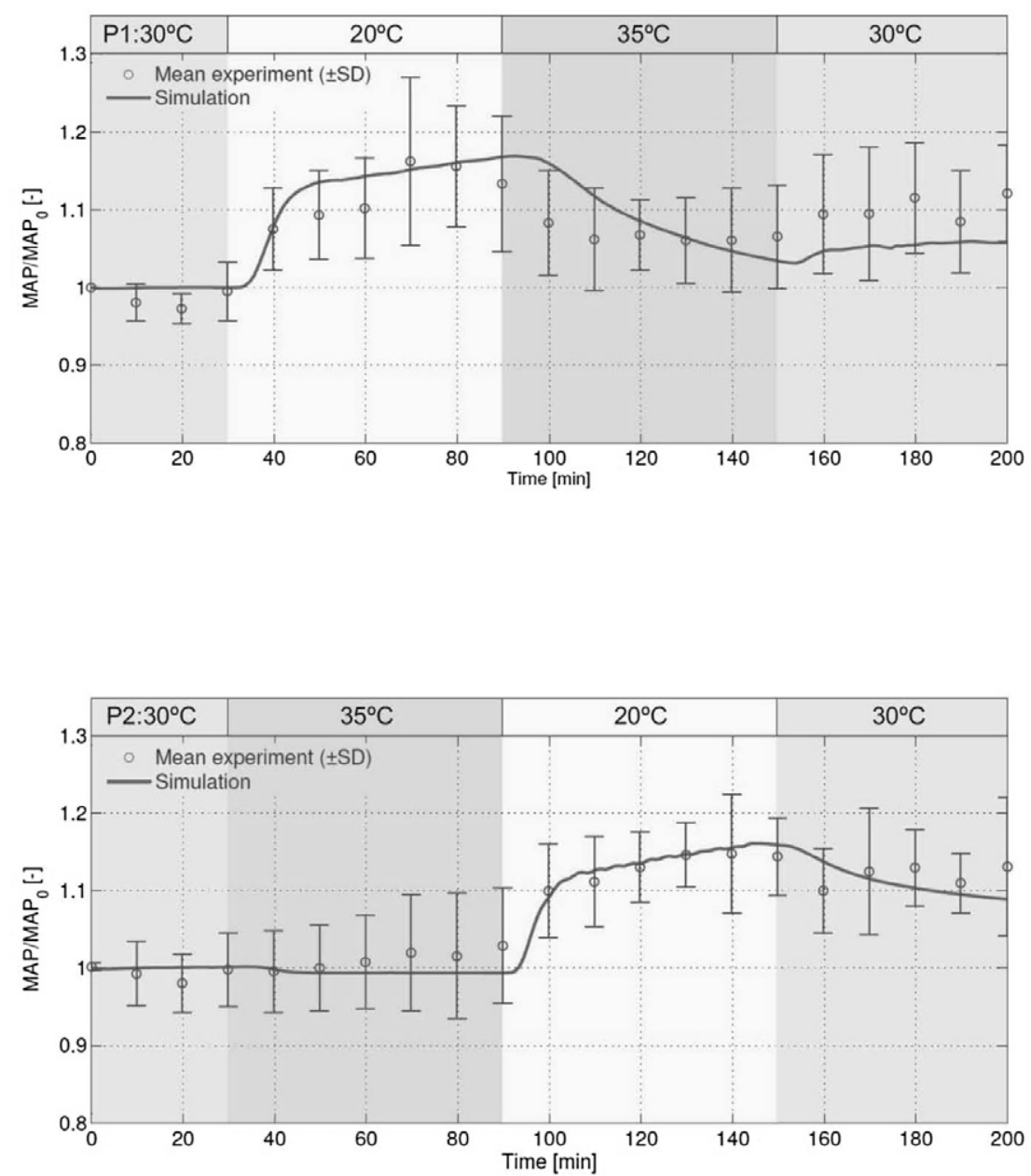

FIG. 6. Evaluation study. Normalized MAP: simulation versus experiment, elderly subjects $(n=10)$, protocol for ambient air temperature P1 (top) and P2 (bottom). simulated MAP are presented in Fig. 6. Measurement data points ( \pm standard deviation $[\mathrm{SD}])$ are plotted in the same graph as well.

In protocol P1, MAP remains constant in the first $30 \mathrm{~min}$ because the subject is in thermal neutral state. Ambient air temperature decreases to $20^{\circ} \mathrm{C}$ over a 15 -min period after which blood pressure rises as a consequence of vasoconstriction. The gradient of MAP is highly dependent on arterial compliance where a low compliance is characteristic for a steep gradient. MAP keeps on rising for the next $60 \mathrm{~min}$ with a lower gradient because skin blood flow approaches its minimal value. When ambient air temperature is changed to $35^{\circ} \mathrm{C}$, less vasoconstriction is observed, resulting in a decreased MAP. The active increase in skin volume $\left(V_{s k}\right)$ observed in heated subjects (18) is neglected in the model, which can possibly explain the delayed simulated fall in MAP. At $t=150 \mathrm{~min}$, ambient air temperature is just declining to $30^{\circ} \mathrm{C}$ where vasoconstriction causes the blood pressure to increase.
The second protocol (P2) is equal to P1 in the first $30 \mathrm{~min}$. In the next stage of the experiment, air temperature is set to $35^{\circ} \mathrm{C}$. In this period, sweating is observed, whereby skin temperature is restrained to rise excessively; this explains the minor change in MAP over this period. Blood pressure increases again due to vasoconstriction when ambient air temperature falls to $20^{\circ} \mathrm{C}$ and declines again in the $30^{\circ} \mathrm{C}$ phase to a value above baseline.

\section{HD COMBINED WITH UF (EVALUATION 2)}

The TP-CV model can ultimately be applied to HD + UF while accounting for thermal and hypovolemic effects on the CV system. Simulations and measurements were done for thermoneutral dialysis where no energy is transferred from patient to extracorporeal circuit $(\mathrm{ET}=0)$ as well as for isothermal dialysis in which core temperature is kept constant $\left(\Delta T_{h y}=0\right)$ by adjusting the blood temperature in the venous line. In the simulations, it was 

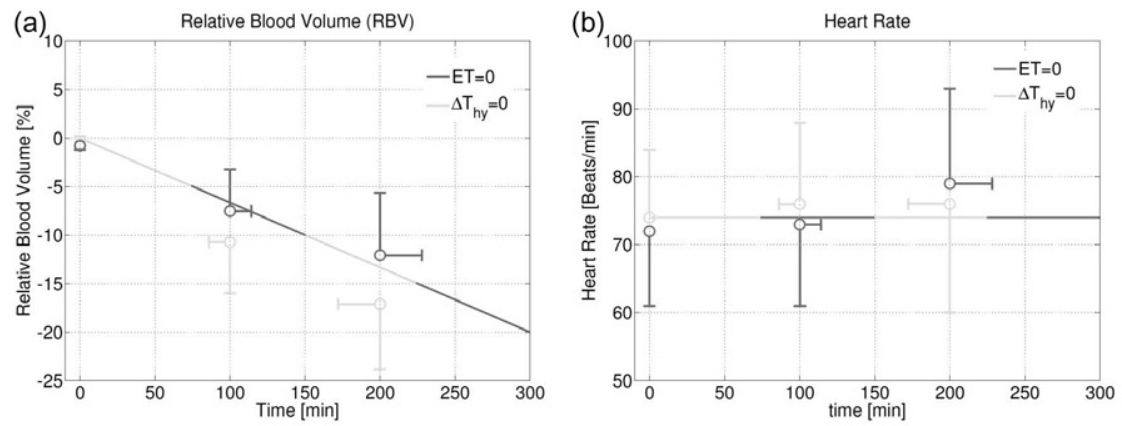

FIG. 7. Model input versus experimental data. Solid lines correspond to model simulations. Linear decrease in RBV for both sessions $(-20 \%$ in $300 \mathrm{~min})$ are indicated by the dashed gray-dark gray line (a). Constant heart rate (HR) input for both sessions is indicated by the dashed gray-dark gray line (b). Experimental data plots (mean \pm SD) were obtained from van der Sande et al. (22). Dark gray error bars illustrate thermoneutral dialysis; gray error bars represent isothermal dialysis. Horizontal error bars illustrate the time variation between the measurement points. For clarity, only one side of the error bar is visualized.

assumed that the patients were initially in a thermoneutral state, because they are feeling thermal comfortable at the beginning of the dialyses. In the model, a "standard man" was used, and the following clothing was taken into account: socks (0.02 clo), briefs $(0.04 \mathrm{clo})$, trousers $(0.28 \mathrm{clo})$, and a sweater ( 0.37 clo $)$. The insulation by a duvet $(0.5$ clo $)$ was modeled as well.

\section{Materials and methods}

Data were received from a previous published study in which 13 stable patients (age 55.23 \pm 13.5 years) on chronic intermittent HD were studied (22). High-efficiency HD was delivered by volumetric machines (A2008H; Fresenius Medical Care, Walnut Creek, CA, USA) and polysulfone dialyzers (F8 and F80; Fresenius Medical Care) using ultrapure bicarbonate dialysate (Diasafe; Fresenius Medical Care). Blood flow was $400 \mathrm{~mL} / \mathrm{min}$, and dialysate flow was $800 \mathrm{~mL} / \mathrm{min}$. Arterial and venous blood line temperatures, core temperature, and ET between the extracorporeal circuit and the patient were monitored noninvasively by a blood temperature monitor (Fresenius Medical Care, Bad Homburg, Germany). Changes in BV were monitored continuously and noninvasively with the Fresenius BV monitor (Fresenius Medical Care). All patients gave informed consent to participate in this study, which was approved by the Beth Israel Medical Center Institutional Review Board (New York). The ambient air temperature was $23^{\circ} \mathrm{C}$ and relative humidity $40 \%$ for the mathematical model. Assumptions have been made on input values for wall temperature $\left(23^{\circ} \mathrm{C}\right)$, airspeed $(0.05 \mathrm{~m} / \mathrm{s})$, and initial shunt flow $(1.0 \mathrm{~L} / \mathrm{min})$ because measurement data were lacking.

\section{Results}

Figure 7a,b shows the model input. In Fig. 8a-f, final results for circulatory and thermal response of isothermal versus thermoneutral $\mathrm{HD}+\mathrm{UF}$ are presented. Dark gray lines indicate thermoneutral dialysis where no ET between patient and extracorporeal circuit takes place $(\mathrm{ET}=0)$. Gray lines represent isothermal dialysis $\Delta T_{h y}=0$. Experimental data plots (mean $\pm \mathrm{SD}$ ) obtained from van der Sande et al. (22) are plotted in the corresponding graph. For clarity, only one side of the error bar is visualized. Measurements were performed at the beginning, halfway, and at the end of the HD treatment. Horizontal error bars indicate the time variation between the measurement points.

Based on experimental data (29), BV is set to decline linearly by $20 \%$ in a 5 -h timeframe for both sessions (Fig. 7a). HR was assumed to be constant in time because the same trend in mean experimental data was observed (22) (Fig. 7b). During thermoneutral dialysis, simulated core temperature difference was predicted to be $0.23^{\circ} \mathrm{C}$ versus $0.32 \pm 0.41^{\circ} \mathrm{C}$ after $200 \mathrm{~min}$ by measurements (Fig. 8a). Oscillations in the gray line (Fig. 8a) originate from the dialysate temperature control model. Simulated skin temperature $\left(T_{s k}\right)$ of the anterior side of the forearm (Fig. 8b) shows a reduction in both sessions $\left(\Delta T_{s k}=-0.52^{\circ} \mathrm{C}\right.$ for $\mathrm{ET}=0$ and $\Delta T_{s k}=-1.84^{\circ} \mathrm{C}$ for $\left.\Delta T_{h y}=0\right)$. The slope discontinuity in skin temperature just after $100 \mathrm{~min}$ during the thermoneutral session was caused by moderate sweating activated by the increase in core temperature. In the case of isothermal HD + UF, core temperature is kept constant by controlling the extracorporeal blood temperature. Model calculations showed that an average rate of $-8.7 \mathrm{~W}$ was transferred to keep core temperature constant. In clinical 

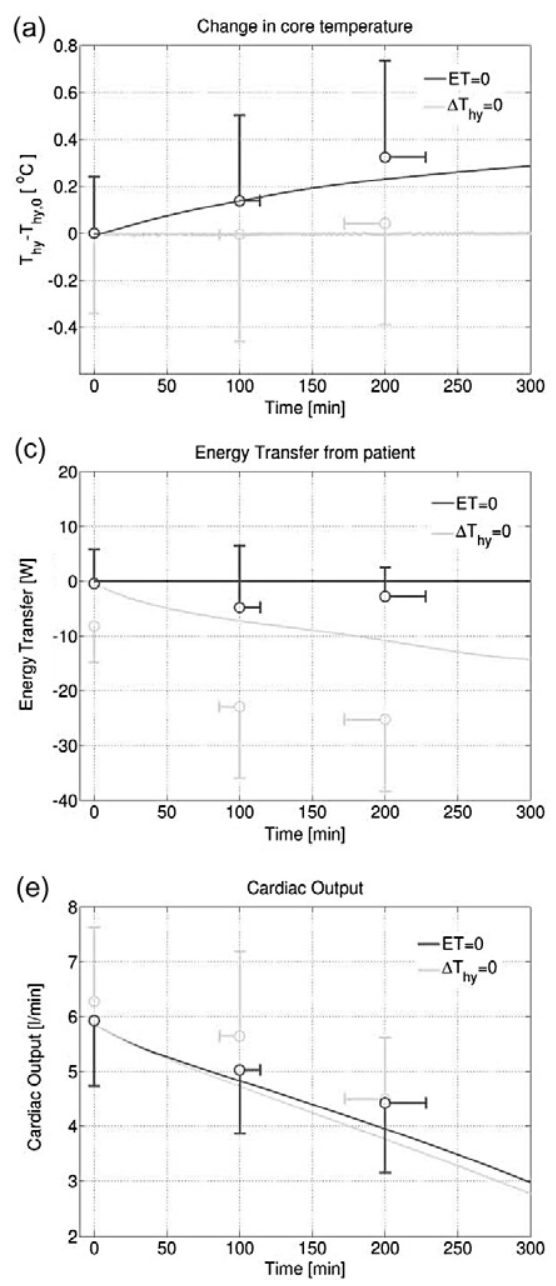
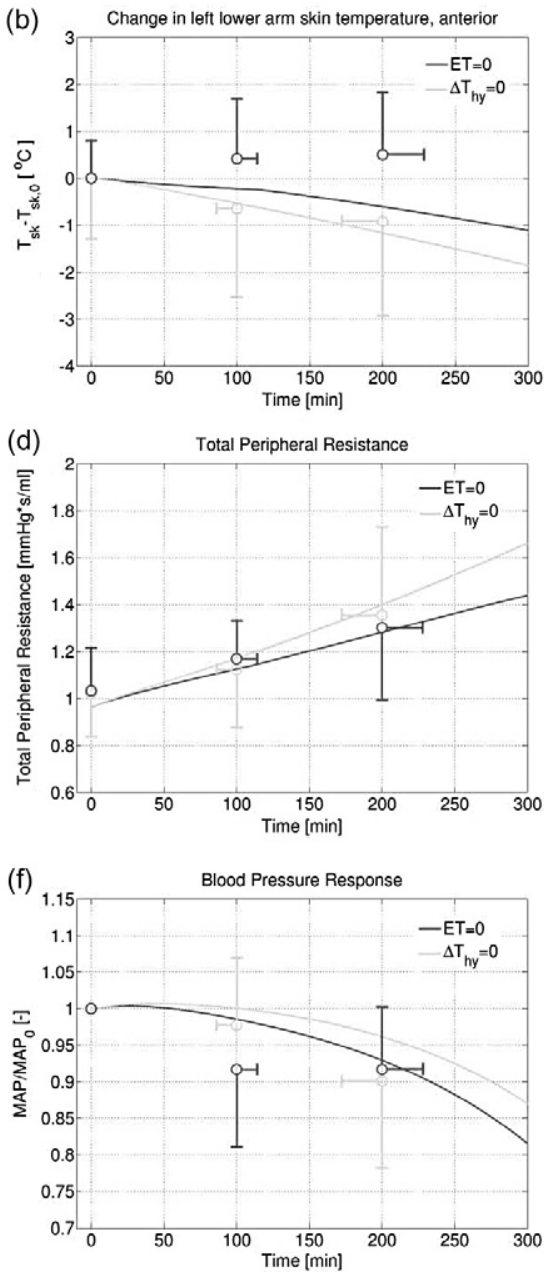

FIG. 8. Model results versus experimental data. Solid lines correspond to model simulations. Circulatory and thermal responses to isothermal $\left(\Delta \mathrm{T}_{\mathrm{hy}}=0\right) \mathrm{com}$ pared with thermoneutral dialysis $(\mathrm{ET}=0)$ for a person with normal clothing in supine position on a bed. Dark gray lines indicate thermoneutral dialysis, gray lines represent isothermal dialysis. Experimental data plots (mean $\pm S D$ ) were obtained from van der Sande et al. (22). Horizontal error bars indicate the time variation between the measurement points. For clarity, only one side of the error bar is visualized. $T_{\text {air }}=23^{\circ} \mathrm{C}, \mathrm{T}_{\text {wall }}=23^{\circ} \mathrm{C}$. Change in core temperature (a), change in left lower arm skin temperature (b), energy transfer (c), total peripheral resistance (d), cardiac output (e), and blood pressure response (f). practice, mean-measured ET rate was $-17 \mathrm{~W} \pm 6 \mathrm{~W}$ including heat removal by the ultrafiltrate (24). This effect was neglected in our calculation because the UFR was small compared with the total blood flow through the dialysis machine. ET was set to be zero for thermoneutral dialysis in the model, despite the same setting in the clinical situation change in ET was $-2.6 \pm 7.6 \mathrm{~W}$ (Fig. 8c). Absolute values for TPR are in the same order as measured as well as the rate of change. Although a clear difference in TPR, end value is simulated between $\Delta T_{h y}=0$ and $\mathrm{ET}=0$ $\left(\Delta \mathrm{TPR}=0.23 \mathrm{~mm} \mathrm{Hg} \mathrm{s} / \mathrm{mL}^{-1}\right)$. No significant difference can be found in the experimental data $(P=$ 0.294) (Fig. 8d). A rise in TPR lowers pressure in the right atrium and results in a decrease in $\mathrm{CO}$ in the course of the treatment. Prediction of CO in thermoneutral situation is close to mean experimental data values (Fig. 8e). Due to a higher TPR predicted by the model in isothermal case, $\mathrm{CO}$ is lower over the whole domain than measured in the isothermal case. Experimental data in the $\Delta T_{h y}=0$ procedure show higher values for $\mathrm{CO}$ than the model simulations $(6.27 \pm 1.4-4.5 \pm 1.1 \mathrm{~L} / \mathrm{min}$ vs. $5.9-3.8 \mathrm{~L} / \mathrm{min}$ after $200 \mathrm{~min}$ ). Venous volume changed by $-28 \%$ for simulation with constant core temperature compared with $-29 \%$ without ET. All former variables finally determined MAP for which a normalized plot is presented (Fig. 8f). While plasma water depletion occurs, overcompensation of regulation mechanisms causes blood pressure to rise slightly in the first $50 \mathrm{~min}$. This rise is important because in clinical practice, the rise in blood pressure during fluid withdrawal is also observed. This observation shows the model is able to sense this paradoxal rise in blood pressure. Thereafter, a progressive fall in blood pressure is predicted. Measurement data describe a large range of distribution for blood pressure response; mean average values show a higher blood pressure in case core temperature is kept constant, especially in the first $100 \mathrm{~min}$. After $200 \mathrm{~min}$, MAP has changed by $-8 \pm 9 \%$ during thermoneutral HD + UF where simulation predicts $-7 \%$. During isothermal 
treatment, MAP changed by $-10 \pm 12 \%$ versus $-4 \%$ simulated after $200 \mathrm{~min}$.

\section{DISCUSSION}

The model predicted CO, TPR, and MAP within the range of measurements. Moreover, the simulated trends show good agreement with experimental data.

The main challenge in modeling and validating thermal effects during hypovolemia is the combined effect of baroreceptors and thermoreceptors on (skin) blood flow regulation. Reduction in $\mathrm{CO}$ and an increase in TPR are responsible for alterations in SBF. The exact way of blood flow redistribution in these conditions remains uncertain. SBF is measured in clinical practice with Laser-Doppler devices. These measure relative changes in SBF locally, which makes verifying variations in total SBF during HD very hard to interpret. Moreover, useful measurement data in this field is still lacking. Simulation for the climate tent experiments showed that the model was able to predict blood pressure changes for the heating and cooling protocols in the range of measurement data. An important observation was the good agreement of the typical higher blood pressure end value compared with baseline.

Total difference in core temperature over the treatment period was slightly lower than predicted by the model, suggesting that also other factors play a role with respect to core temperature increase during HD + UF. Moreover, mean experimental data show a rise in lower arm skin temperature during $\mathrm{ET}=0$, which possibly indicates even more heat loss from the skin to environment compared with the model. Note that only thermal and CV effects caused by UF have been modeled, hence no effects by the HD treatment itself. Observations in clinical studies showed an inexplicable increase in core temperature during isovolemic HD (22). Furthermore, decrease in core temperature was more distinct during isolated UF compared with HD + UF for the same removed energy (23).

In the model, less energy had to be removed compared with experimental data to keep core temperature on baseline level. This can partly be explained by neglecting the extracorporal, isothermic heat flow caused by UF (24). Also, the calculation of the ET is very sensitive to the (measured) blood temperature difference over the dialysis machine: Eq. 12 shows that an increase in this blood temperature difference with $0.1^{\circ} \mathrm{C}$ and a flow $Q_{\text {dia,b }}=410 \mathrm{~mL} / \mathrm{min}$ causes an increase in ET of 2.6W. Therefore, accurate measurements of ingoing and outgoing blood temperatures are important. Hypovolemic vasoconstriction prob- ably is also partially involved in the initiating factors behind the rise in core temperature during HD + UF procedures. However, simulations showed that vasoconstriction in itself, theoretically, can be responsible for a substantial rise in core temperature (Fig. 8a). It should be noted that hypovolemic-induced cutaneous vasoconstriction is assumed to react equally on the same skin areas as thermal-induced vasoconstriction would do, although the exact response on SBF alterations during hypovolemia is still under debate (31). Due to the exploratory character of this research, patient-dependent constants in the TP model were chosen for a standard person. In the CV model, these constants were obtained to correlate with mean values of measurements while in clinical practice, each patient reacts differently, which makes it difficult to observe patient-specific thermal and $\mathrm{CV}$ trends in simulated results. Both models have extensively been validated separately $(1,20)$. They have proven to correlate well with experimental data for a wide range of subjects. Because the model developed in this study showed good agreement with mean measurement data, future research should be focused on incorporation and validation of patient-specific characteristics.

No indications of sudden vasodilatation were observed in the simulations executed. Because the exact interaction between baro- and thermoreceptors is not yet fully understood, a simulation was done for the hypothetical scenario when a sudden increase in SBF would occur due to sudden vasodilatation. When total SBF was set to increase from $0.2 \mathrm{~L} / \mathrm{min}$ to $1 \mathrm{~L} / \mathrm{min}$ after $260 \mathrm{~min}$ in a 20 -min period, MAP decreased by an additional $15 \%$ (Fig. 9), which is comparable with values observed in clinical practice.

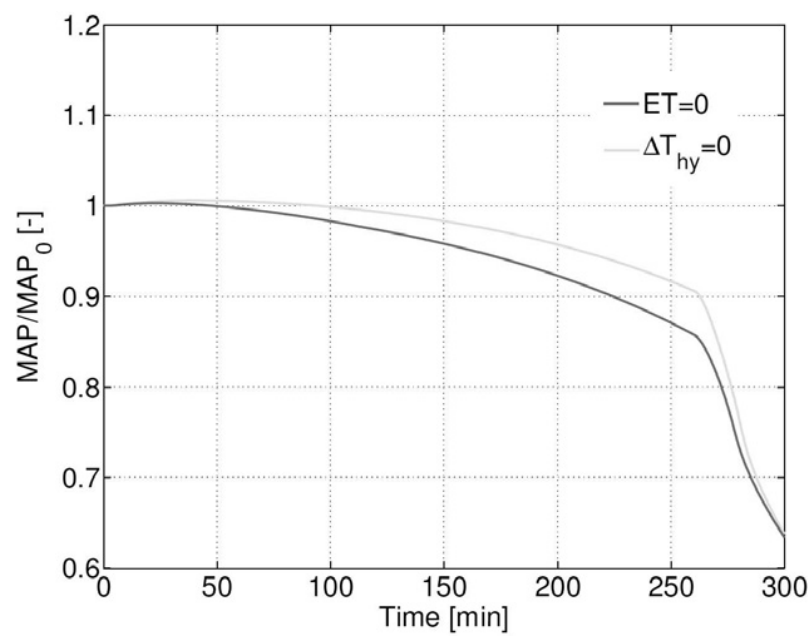

FIG. 9. Simulations showing the effect on MAP by an increase in SBF from $0.2 \mathrm{~L} / \mathrm{min}$ to $1 \mathrm{~L} / \mathrm{min}$ after $260 \mathrm{~min}$ due to sudden vasodilatation. 
If an increase in $\mathrm{CO}$ cannot compensate for the extra need for SBF, dangerous hypotension can occur.

\section{CONCLUSIONS}

In this study, a mathematical model was developed to examine thermal and circulatory effects during HD + UF by coupling a TP model with a simple model of the CV system. Simulation results of the combined model have shown possibilities for predicting circulatory and thermal response during HD + UF. In the long term, this model can help in clinical practice to determine an ideal treatment protocol for each individual patient to minimize complications. In addition, the model can potentially be used for preventing IDH in the course of HD. Evaluation of the coupled model for blood pressure changes caused by variations in ambient temperature offered promising results.

The primary hypothesis of this study was that UF-induced vasoconstriction would result in a reduction of SBF, a decrease in surface heat loss, increase in core temperature, rise in cutaneous blood flow, and finally IDH. Indeed, when cutaneous vasoconstriction was activated for a person with regular clothing in a $23^{\circ} \mathrm{C}$ room, the model showed an increase in core temperature of almost $0.3^{\circ} \mathrm{C}$ within $300 \mathrm{~min}$. This indicates that reduced heat loss from the skin due to vasoconstriction per se can be responsible for a rise in core temperature during HD in the same order as measurements show. Simulation results revealed that an increase in blood flow to the periphery lowers blood pressure substantially but indications for sudden onset of this increased blood flow were not observed. In conclusion, this exploratory study has led to a new simulation model for hypovolemicinduced CV changes while accounting for thermal effects in the course of HD + UF.

Acknowledgments: The authors wish to thank subjects for participating in this study. We also would like to thank all members of the thermoregulation group between Eindhoven University of Technology and Maastricht University for their contribution in this research. Furthermore, the authors are grateful to Karin Krenning (Franciscus Hospital Roosendaal, The Netherlands) for all the stimulating discussions.

\section{REFERENCES}

1. Cavalcanti S, Cavani S, Ciandrini A, Avanzolini G. Mathematical modelling of arterial pressure response to hemodialysisinduced hypovolemia. Comput Biol Med 2006;36:128-44.

2. Barth C, Boer W, Garzoni D, et al. Characteristics of hypotension-prone haemodialysis patients: is there a critical relative blood volume? Nephrol Dial Transplant 2003;18:135360.
3. Nakamura Y, Ikeda T, Takata S, et al. The role of peripheral capacitance and resistance vessels in hypotension following dialysis. Am Heart J 1991;121:1170-7.

4. Gotch FA, Keen ML, Yarian SR. An analysis of thermal regulation in hemodialysis with one and three compartment models. ASAIO 1989;35:622-4.

5. Van der Sande FM, Wystrychowski G, Kooman JP, et al. Control of core temperature and blood pressure stability during hemodialysis.. Clin J Am Soc Nephrol 2009;4:93-8.

6. Damasiewicz MJ, Polkinghorne KR. Intra-dialytic hypotension and blood volume and blood temperature monitoring. Nephrology 2011;16:13-8.

7. Dasselaar JJ, Huisman RM, de Jong PE, Franssen CFM. Measurment of relative blood volume changes during haemodialysis: merits and limitations. Nephrol Dial Transplant 2005; 20:2043-9.

8. Ursino M, Innocenti M. Modeling arterial hypotension during hemodialysis. Artif Organs 1997;21:873-90.

9. Guyton AC, Jones CE, Coleman TG. Circulatory Physiology: Cardiac Output and Its Regulation. Philadelphia, PA: W.B. Saunders Co., 1973.

10. Severens NMW, van Marken Lichtenbelt WD, Frijns AJH, van Steenhoven AA, de Mol BAJM, Sessler DI. A model to predict patient temperature during cardiac surgery. Phys Med Biol 2007;52:5131-45.

11. Fiala D, Lomas K, Stohrer M. A computer model of human thermoregulation for a wide range of environmental conditions: the passive system. J Appl Physiol 1999;87:1957-72.

12. Fiala D, Lomas K, Stohrer M. Computer prediction of human thermoregulatory and temperature responses to a wide range of environmental conditions. Int J Biometeorol 2001;45:14359.

13. Pennes HH. Analysis of tissue and arterial blood temperatures in the resting human forearm. J Appl Physiol 1948;1:93-122.

14. Mitchell JW, Myers GE. An analytical model of the countercurrent heat exchange phenomena. Biophys J 1968;8:897-911.

15. Mackowiak PA, Wasserman SS, Levine MM. A critical appraisal of $98.6^{\circ} \mathrm{F}$, the upper limit of the normal body temperature, and other legacies of Carl Reinhold August Wunderlich. JAMA 1992;268:1578-80.

16. Schmidt-Nielsen K. Animal Physiology. London: Cambridge University Press, 1975.

17. Stolwijk J. A mathematical model of physiological temperature regulation in man. NASA contractor report CR-1855. Washington, DC: NASA; 1971.

18. Rowell LB, Wyss CR. Temperature regulation in exercising and heat stressed man. In: Shitzer A, Eberhart RC, eds. Heat Transfer in Medicine and Biology 1. New York and London: Plenum Press, 1985;53-78.

19. Guyton AC, Hall JE. Textbook of Medical Physiology, 11th Edition. Philadelphia, PA: Elsevier Saunders, 2006.

20. Fiala D. Dynamic simulation of human heat transfer and thermal comfort [dissertation]. Leicester: Montfort University, 1998.

21. van Marken Lichtenbelt WD, Frijns AJH, van Ooijen AMJ, Fiala D, Kester AM, van Steenhoven AA. Validation of an individualized model of human thermoregulation for predicting responses to cold air. Int J Biometeorol 2007;51:169-79.

22. Van der Sande FM, Rosales LM, Brener Z, et al. Effect of ultrafiltration on thermal variables, skin temperature, skin blood flow, and energy expenditure during ultrapure hemodialysis. J Am Soc Nephrol 2005;16:1824-31.

23. Van der Sande FM. Strategies for improving hemodynamic stability during hemodialysis [dissertation]. Maastricht: Maastricht University, 1999.

24. Rosales LM, Schneditz D, Morris AT, Rahmati S, Levin NW. Isothermic hemodialysis and ultrafiltration. Am J Kidney Dis 2000;36:353-61.

25. Cavalcanti S, Di Marco LY. Numerical simulation of the hemodynamic response to hemodialysis-induced hypovolemia. Artif Organs 1999;23:1063-73. 
26. Frank O. Die Grundform des arteriellen Pulses. Z Biol 1899;37:483-526.

27. Cavani S, Cavalcanti S, Avanzolini G. Model based analysis of arterial pressure response to hemodialysis induced hypovolemia. ASAIO J 2001;47:377-88.

28. Keller DM, Davis SL, Low DA, Shibasaki M, Raven PB, Crandall CG. Carotid baroreceptor stimulation alters cutaneous vascular conductance during whole body heating in humans. J Physiol 2006;577:925-33.

29. Krepel HP, Nette RW, Akçahüseyin E, Weimar W, Zietse R. Variability of relative blood volume during haemodialysis. Nephrol Dial Transplant 2000;15:673-9.
30. Kingma BRM, Frijns AJH, Saris WHM, van Steenhoven AA, van Marken Lichtenbelt WD. Increased systolic blood pressure after mild cold and rewarming: relation to cold-induced thermogenesis and age. Acta Physiol 2011;203:419-27.

31. Mistrík E, Sulková DS, Bláha V. Evaluation of skin microcirculation during hemodialysis. Ren Fail 2010;32:21-6.

32. Selby NM, Burton JO, Chesterton LJ, Mcintyre CW. Dialysisinduced regional left ventricular dysfunction ameliorated by cooling the dialysate. Clin J Am Soc Nephrol 2006;1:1216-25.

\section{APPENDIX}

\section{Model constants}

\section{TP model}

\begin{tabular}{|c|c|c|c|}
\hline Parameter & Description & Value & Unit \\
\hline$\alpha_{\mathrm{cs}}$ & Sensitivity of baroreflex on Cs & 0.5 & - \\
\hline$B W$ & Body weight & 73 & $\mathrm{~kg}$ \\
\hline$c_{\mathrm{b}}$ & Specific heat of blood & 3640 & $\mathrm{~J} / \mathrm{kg} / \mathrm{K}$ \\
\hline$\rho_{\mathrm{b}}$ & Density of blood & 1052 & $\mathrm{~kg} / \mathrm{m}^{3}$ \\
\hline$k$ & Tissue's thermal conductivity & 0.66 & $\mathrm{~W} / \mathrm{m} / \mathrm{K}$ \\
\hline$K_{\mathrm{cs}}$ & Saturation baroreflex on Cs & 180 & - \\
\hline$\eta$ & Stability factor & $1 / 80$ & - \\
\hline$Q_{\text {dia }}$ & Blood flow through dialysis machine & 400 & $\mathrm{~mL} / \mathrm{min}$ \\
\hline$Q_{10}$ & Van 't Hoff Q10 factor & 2 & - \\
\hline$T_{\text {air }}$ & Air temperature & 23 & ${ }^{\circ} \mathrm{C}$ \\
\hline$T_{\text {wall }}$ & Wall temperature & 23 & ${ }^{\circ} \mathrm{C}$ \\
\hline$\mu_{\mathrm{b}}$ & Proportionality factor by Stolwijk & 0.932 & $1 / \mathrm{K}$ \\
\hline$v_{\text {air }}$ & Airspeed & 0.05 & $\mathrm{~m} / \mathrm{s}$ \\
\hline
\end{tabular}

N.B. Additional TP-model parameter values are registered in Severens et al. (10).

\section{CV model}

\begin{tabular}{|c|c|c|c|}
\hline Parameter & Description & Value & Unit \\
\hline$C_{\mathrm{a}}$ & Compliance of arterial circulation & 1 & $\mathrm{~mm} \mathrm{Hg} / \mathrm{mL}$ \\
\hline$C_{\mathrm{f}}$ & Compliance of fistula circulation & 0.01 & $\mathrm{~mm} \mathrm{Hg} / \mathrm{mL}$ \\
\hline$C_{\mathrm{m}}$ & Compliance of micro circulation & 9.2 & $\mathrm{~mm} \mathrm{Hg} / \mathrm{mL}$ \\
\hline$C_{\mathrm{sk}}$ & Compliance of skin circulation & 9.2 & $\mathrm{~mm} \mathrm{Hg} / \mathrm{mL}$ \\
\hline$C_{\mathrm{ra}}$ & Compliance of right atrium & 33.12 & $\mathrm{~mm} \mathrm{Hg} / \mathrm{mL}$ \\
\hline$C_{\mathrm{v}}$ & Compliance of venous circulation & 20.6 & $\mathrm{~mm} \mathrm{Hg} / \mathrm{mL}$ \\
\hline$f$ & Heart rate & 74 & beats/min \\
\hline$f_{\mathrm{e}}$ & Initial heart rate & 74 & beats/min \\
\hline$K_{\text {aff }}$ & Baroreceptor balance parameter & -0.88 & - \\
\hline$K_{\mathrm{co}}$ & Sensitivity parameter of heart rate & 0.06 & - \\
\hline$K_{\mathrm{v}}$ & Regulation efficiency of $\mathrm{V}_{\mathrm{vu}}$ & 0.22 & - \\
\hline$K_{\mathrm{r}}$ & Regulation efficiency of $\mathrm{R}_{\mathrm{m}}$ & 0.5 & - \\
\hline$\varphi$ & Proportionality factor for $\mathrm{R}_{\mathrm{a}}$ to $\mathrm{R}_{\mathrm{sk}}$ & $1 / 56$ & - \\
\hline$p_{\mathrm{ae}}$ & Initial mean arterial pressure & 95 & $\mathrm{~mm} \mathrm{Hg}$ \\
\hline$p_{\text {ran }}$ & Sensitivity of cardiac output to $p_{r a}$ & 1.8 & $\mathrm{~mm} \mathrm{Hg}$ \\
\hline$p_{\text {ras }}$ & $p_{r a}$ for null cardiac output & -0.64 & $\mathrm{~mm} \mathrm{Hg}$ \\
\hline$R_{\mathrm{f}}$ & Fistula resistance & 3.6 & $\mathrm{~mm} \mathrm{Hg} \mathrm{s} / \mathrm{mL}$ \\
\hline$R_{\text {me }}$ & Initial microcirculatory resistance & 0.6 & $\mathrm{~mm} \mathrm{Hg} \mathrm{s} / \mathrm{mL}$ \\
\hline$R_{\text {ske }}$ & Intial skin resistance & 9.0 & $\mathrm{~mm} \mathrm{Hg} \mathrm{s} / \mathrm{mL}$ \\
\hline$R_{\mathrm{ra}}$ & Inflow resistance of right atrium & 0.09 & $\mathrm{~mm} \mathrm{Hg} \mathrm{s/mL}$ \\
\hline$R_{\mathrm{v}}$ & Resistance of venous circulation & 0.22 & $\mathrm{~mm} \mathrm{Hg} \mathrm{s/mL}$ \\
\hline$\tau$ & Baroreflex time constant & 10 & $\mathrm{~s}$ \\
\hline$V_{\text {fu }}$ & Unstressed fistula volume & 0 & $\mathrm{~mL}$ \\
\hline$V_{\mathrm{mu}}$ & Unstressed microcirculatory volume & 60 & $\mathrm{~mL}$ \\
\hline$V_{\text {sku }}$ & Unstressed skin volume & 40 & $\mathrm{~mL}$ \\
\hline$V_{\text {vue }}$ & Initial unstressed venous volume & 1700 & $\mathrm{~mL}$ \\
\hline$V_{\text {tote }}$ & Initial total blood volume & 3807 & $\mathrm{~mL}$ \\
\hline$Q_{\mathrm{m}}$ & Maximum cardiac output & 154 & $\mathrm{~mL} / \mathrm{s}$ \\
\hline
\end{tabular}

